\title{
Numerical Simulation of Electroactive Hydrogels for Cartilage-Tissue Engineering
}

\author{
Abdul Razzaq Farooqi ${ }^{1,2, *}$, Julius Zimmermann ${ }^{1}{ }^{\complement}$, Rainer Bader ${ }^{3,4}$ and \\ Ursula van Rienen 1,4 (D) \\ 1 Institute of General Electrical Engineering, University of Rostock, 18051 Rostock, Germany \\ Department of Electronics Engineering, The Islamia University of Bahawalpur, 63100 Bahawalpur, Pakistan \\ Department of Orthopaedics, University Medical Center Rostock, 18057 Rostock, Germany \\ 4 Department Life, Light \& Matter, University of Rostock, 18051 Rostock, Germany \\ * Correspondence: abdul.farooqi@uni-rostock.de
}

Received: 28 June 2019; Accepted: 4 September 2019; Published: 9 September 2019

\begin{abstract}
The intrinsic regeneration potential of hyaline cartilage is highly limited due to the absence of blood vessels, lymphatics, and nerves, as well as a low cell turnover within the tissue. Despite various advancements in the field of regenerative medicine, it remains a challenge to remedy articular cartilage defects resulting from trauma, aging, or osteoarthritis. Among various approaches, tissue engineering using tailored electroactive scaffolds has evolved as a promising strategy to repair damaged cartilage tissue. In this approach, hydrogel scaffolds are used as artificial extracellular matrices, and electric stimulation is applied to facilitate proliferation, differentiation, and cell growth at the defect site. In this regard, we present a simulation model of electroactive hydrogels to be used for cartilage-tissue engineering employing open-source finite-element software FEniCS together with a Python interface. The proposed mathematical formulation was first validated with an example from the literature. Then, we computed the effect of electric stimulation on a circular hydrogel sample that served as a model for a cartilage-repair implant.
\end{abstract}

Keywords: electrical stimulation; articular cartilage; cartilage-tissue engineering; electrically conductive hydrogels; scaffold; computational modelling

\section{Introduction}

Articular hyaline cartilage is an inhomogeneous, hierarchically ordered, and multiphasic tissue that covers opposing bone surfaces in diarthroidal joints [1]. It is an avascular tissue comprised of chondrocytes surrounded by the extracellular matrix (ECM) [2]. Chondrocytes are responsible for synthesizing and maintaining the ECM [3], which mainly consists of collagen fibers, proteoglycans, and the interstitial fluid phase [4]. Based on a distinct matrix composition and cellular properties, different zones of articular cartilage can be distinguished [5,6]. The compositional and structural environment of the tissue is altered due to the progression of osteoarthritis or injury $[7,8]$. Ideally, such alterations should be reversed for the proper functionality of the tissue.

Hydrogels are three-dimensional polymeric networks of high water-uptake capacity, being capable of mimicing native tissue environments [9]. Due to the potential of tailoring the structural and compositional properties of hydrogels toward relevant biological types of tissue, they are considered optimal for becoming a substitute for damaged tissue [10]. In cartilage-tissue engineering, hydrogels should provide adequate mechanical strength, physiological swelling, lubrication, and piezoelectric behavior to replicate the biomimetic environment, similar to native articular cartilage $[9,11]$. With tissue-engineered hydrogel scaffolds fabricated from biologically derived or 
synthesized polymeric materials featuring controlled degradation profiles, opening voltage-activated channels can be achieved using external stimuli [12].

Since articular cartilage is essentially a form of a natural polyelectrolyte hydrogel $[13,14]$, electroactive hydrogel scaffolds are a promising approach to mimic its properties to improve cartilage-tissue engineering strategies [15]. The chondrogenic phenotype of chondrocytes inside these hydrogel matrices can be maintained by applying suitable biophysical stimuli [16]. Various biophysical stimuli like mechanical [17], electrical [18,19], and pulsed electromagnetic fields (PEMF) [20,21] were reported for in silico, in vitro, and in vivo applications. In these approaches, electrical stimulation is one of the beneficial methods for enhancing cartilage-tissue repair and regeneration, while it has been less investigated as compared to mechanical stimulation and PEMF [22]. The electrical-stimulation response of articular cartilage has been investigated mainly in vitro and in few in vivo studies. There, the focus was on the medical and biological part of the experiment, while the electrical part has not often been investigated in detail. An option to shed light on the electrical processes are in silico studies. To date, only few studies have been performed in silico [18]. Thus, there is a need for in silico studies to enhance the understanding of the electrical effects and subsequently find an optimal protocol for neocartilage-tissue engineering.

There are two basic methods to apply electrical stimulation to in vitro cultures or in vivo animal models [23]. The first scheme uses electrodes that are in direct contact with the biological sample, while the second scheme consists of an indirect coupling system with electrodes separated from the sample [24]. The input for the case of direct contact can either be a stationary (direct-current) or time-varying (alternating-current) signal, while input for indirect coupling is only the time-varying signal. The indirect coupling can either be inductively coupled (IC) or capacitively coupled (CC) [18,24]. A subtype of the IC is the PEMF, which originates from the natural strain-generated potentials observed in bones [23]. Specifically, it is hypothesized that PEMF causes the bone to deform in a similar manner as due to an external load [25].

There exist subtypes of the basic stimulation methods as well as to optimize the electrical stimulation. For example, in the direct-contact scheme, the electrically exposed sample could be isolated from the reactive products of electrolysis stemming from redox reactions occurring at the electrode surface [26] by using agar salt bridges [27]. In the current study, we suggest a setup that isolates the sample from those reactive electrolysis products. Similarly, for indirect coupling, in order to have optimized stimulation, the capacitive and inductive stimuli can be combined in a single setup [28]. The chondrogenic differentiation of cartilage can be enhanced by the application of either direct or indirect stimulation.

Hydrogels can be used either as acellular scaffolds or as cell-seeded biomaterials for healing the articular-cartilage defect using tissue-engineering approaches [16]. Acellular scaffolds function as cellfree implants replacing weak or damaged cartilage tissue. Efforts are made to engineer acellular biomaterial scaffolds to replicate the architectural features, mechanical properties, and thus biological functions of native cartilage tissue $[29,30]$. Using cell-biomaterial combinations, the concept is to deliver suitable cell-laden biomaterials as artificial ECM to promote chondrocyte attachment and matrix formation at the defect site [29]. The aim is to present the residing cells' developmental and microenvironmental cues to trigger chondrogenesis by the presence of the surrounding hydrogel that can be further enhanced by the application of external biophysical stimuli [31,32].

The aim of the current numerical study was to analyze the distribution of ions and the electric potential in a hydrogel scaffold and the surrounding medium that can be used for designing electrical-stimulation experiments and studying the interactions of chondrocyte-seeded hydrogels at the microscale. In Section 2, we briefly discuss the state of the art that has been reported using either direct or indirect electrical stimulation for chondrocytes, cartilage tissue, or cell-seeded hydrogels. In Section 3, an open-source software framework is described for the finite-element simulation of electroactive scaffolds using cartilage-tissue engineering. In Section 4, we report solutions of a validated finite-element model and an extension of the model using circular geometry. 


\section{Electrical-Stimulation Studies of Articular Cartilage}

\subsection{Direct Coupling}

\subsubsection{In Vivo Studies}

As early as 1974, Baker et al. [33] observed the enhancement of the latent potential for the repair of hyaline cartilage in New Zealand white rabbits by using a bimetallic device inserted into articular-cartilage defects. The repair response appeared to stem from proliferating chondrocytes and spread from the defect margin over the entire surface of the defect [33]. Later, they also reported that the regrowing potential of articular hyaline cartilage at the defect site could be enhanced by changing the electrochemical environment by the application of electrical stimulation [34]. Lippiello et al. [35] observed improved repair quality of the articular cartilage by application of a pulsing direct current to rabbit joints in which an osteochondral defect was surgically created.

\subsubsection{In Vitro Studies}

Electrokinetic transduction in cartilage occurs due to the presence of charged groups of the macromolecules in the ECM, mostly the proteoglycans. Frank et al. [36,37] experimentally and theoretically demonstrated this transduction phenomenon in bovine articular-cartilage tissue. Later, current-generated stress was also measured, and its dependence on the applied current's amplitude and frequency was characterized [38]. Similarly, Akkin et al. [39] and Youn et al. [40] studied this phenomenon using phase-sensitive optical low coherence reflectometry (PS-OLCR) and differential-phase optical coherence tomography (DP-OCT), respectively.

In the doctoral thesis of Gray, the response of an epiphyseal plate in organ culture was determined over a current-density range of 50 to $1000 \mu \mathrm{A} \mathrm{cm}^{-2}$ at frequencies between 0.1 and $100 \mathrm{~Hz}$ [41]. The motivation for these experiments was to examine the sensitivity of chondrocytes to currents similar in magnitude and frequency to those expected to occur in in vivoloading situations. MacGinitie et al. [42,43] developed an experimental model to observe the effect of electrical stimulation on cartilage tissue manifesting itself in field-induced changes of stress protein and total protein synthesis. Furthermore, the choice of electrical parameters such as frequency and field magnitude that could influence the protein synthesis in cartilage explants were addressed [44]. Nogami et al. [45] investigated the effect of direct current electrical stimulation of $5 \mu \mathrm{A}$ on mesenchymal cell differentiation into cartilage using bone matrix gelatin and fetal rat muscle.

Since the ability to guide chondrocyte movement may pave the way for strategies to achieve cartilage healing or repair and for further development of cartilage substitutes, Chao et al. [46] reported that cathodal migration occurs for cultured chondrocytes subjected to directly coupled electrical stimulation. Furthermore, an electric field was applied to chondrocytes seeded in a homogeneous agarose culture system and the changes in cell proliferation and ECM biosynthesis were quantified with an emphasis on the cellular signaling pathways responsible for the observed changes [27].

Using the 3D chondrocyte-agarose model system, Akanji et al. [47] investigated the effects of direct current on matrix synthesis and cell proliferation. Kwon et al. [48] investigated the effect of electrical stimulation during chondrogenesis of mesenchymal stem cells (MSCs). Most recently, it was observed by Hiemer et al. [49] that exposure to a directly connected alternating electric field (700 $\mathrm{mV}$, $1 \mathrm{kHz}$ ) significantly increased the synthesis of collagen type II in human chondrocytes under hypoxic culture conditions.

\subsection{Indirect Coupling}

\subsubsection{In Vivo Studies}

Farr et al. [50] used a CC device in 288 patients with knee osteoarthritis and reported that those patients who received electrical stimulation for more than $750 \mathrm{~h}$, profited from pain relief and hence 
decrease in anti-inflammatory drug use. Moreover, Garland et al. [51] reported that an optimized CC electrical stimulation device for treating knee OA significantly improved symptoms and function without causing any significant side effects.

\subsubsection{In Vitro Studies}

Rodan et al. [52] demonstrated that an external, capacitively coupled electric stimulation (CCES) applied to chondrocytes in suspension stimulates DNA synthesis. This effect could be attributed to $\mathrm{Ca}^{+2}$ and $\mathrm{Na}^{+}$fluxes. Fitzsimmons et al. [53] used the CC-pulsed electric field for human chondrocytes and, based on the results, suggested that nitric oxide is involved in the transduction pathway for chondrocyte proliferation, and that its production may be the result of a cascade involving calcium, calmodulin, and cGMP production. The CCES with $60 \mathrm{kHz}$ and $20 \mathrm{mV} / \mathrm{cm}$ was found to be a proper and effective inducer of differentiation of human adipose-derived stem cells (ADSCs) into the chondrogenic direction [54]. Later, the same study was extended with a frequency of $1 \mathrm{kHz}$ [55] showing the same principal results.

The group of Brighton et al. conducted many studies on the effect of CCES on chondrocyte proliferation [56-61]. In one of their first studies, they observed that articular cartilage chondrocytes from Holstein calf in pellet form showed increased glycosaminoglycan synthesis or increased cell proliferation by appropriate CCES [56]. Similarly, they observed upregulation of gene expression as well as the matrix accumulation of structural cartilage macromolecules (such as type II collagen and aggrecan) with specific CCES in vitro [57]. Later, this study was extended to adult bovine articular cartilage explants, and similar positive results could be reported [58].

Brighton et al. [59] observed significant upregulation of cartilage matrix protein expression and production while simultaneously significantly attenuating the upregulation of metalloproteinase expression by the use of CCES. Thus, it was concluded that the use of electrical stimulation to both diminish matrix destruction and increase matrix production has promising potential to noninvasively treat osteoarthritis patients. The mechanisms through which CCES stimulates matrix production and inhibits matrix destruction were previously unknown. Thus, $\mathrm{Xu}$ et al. [60] conducted a study to ascertain that the effect of electrical stimulation does not involve intracellular $\mathrm{Ca}^{+2}$ repositories but solely extracellular $\mathrm{Ca}^{+2}$ influx via voltage-gated calcium channels. At the same time, calmodulin, calcineurin, and the nuclear factor of activated T-cells (NF-AT) decrease rather than phospholipase C and $\mathrm{IP}_{3}$. Finally, they reported the use of reflectance spectrophotometric analysis to demonstrate the structural modification of osteoarthritic articular human cartilage explants [61].

The capability of adipose-derived stem cells was assessed to differentiate into osteocytes, chondrocytes, or adipocytes. Clear patterns of differentiation into three cell lineages were observed after two weeks in differentiating medium [62]. Recently, Vaca-González et al. [63] presented a combined computational and experimental approach to better understand hyaline-cartilage biology and its response to electrical stimulation using different in vitro models in three different scenarios. Initially, cell proliferation and the glycosaminoglycans synthesis of chondrocytes, cultured in a monolayer and stimulated with electric fields, were analyzed. Then, histomorphometric analysis was performed to chondroepiphysis explants that were electrically stimulated [64]. Finally, the effects of electrical stimulation on chondrogenic differentiation of mesenchymal stem cells cultured in hydrogels were assessed [65].

\section{Electroactive Scaffolds for Cartilage-Tissue Engineering}

In general, developing a computational or mathematical model presents a critical prerequisite to design informative and comprehensible experiments [66]. These models can be used to replicate the physical experiments and can be manipulated in ways that would otherwise be too costly and complex. The modeling approach enables to simulate surgical conditions without damaging the biological specimen. Hence, experiments can be easily optimized with respect to electrical-input parameters. Another factor that may make incorporating computational models into experiments 
seem less daunting is that even solving a single simple equation can improve an experiment design [66], as repeating experiments is difficult due to ethical, logistical, and budgetary constraints. Various cartilage-tissue engineering approaches were experimentally performed but appropriate computational models are still lacking [67-69]. Keeping this in mind, we propose an open-source simulation workflow to develop better experiment procedure for cartilage-tissue engineering using electrical stimulation.

It is known that application of electrical-stimulation results in ion motion and the opening of voltage-gated calcium channels [70]. The increased activity of intracellular-calcium concentration activates the underlying mechanisms that facilitate cell growth, proliferation, and differentiation in a tissue-engineered sample. The complete tissue-engineering approach is schematically described in Figure 1. In our current study, we are only concerned with the in vitro electrical stimulation part of the tissue-engineering approach as illustrated in Figure 2. By means of numerical simulations, these mechanisms can be studied at different-length scales.

The sample consisting of a hydrogel embedded with chondrocytes was immersed in $\mathrm{NaCl}$ solution subject to an externally applied electrical stimulation as shown in Figure 2. The implementation of the simulation model consisted of solving nonlinear coupled Poisson-Nernst-Planck (PNP) partial differential equations (PDEs) numerically using FEniCS to find the distribution of the electric potential, and the concentration of anions and cations with the given set of boundary conditions. The distinction between hydrogel and solution phases was realized by using different material parameters for each domain. The most important feature of the hydrogel phase in this model was the presence of bound anionic charges $c^{f}$ with $z^{f}$ valence. The complete mathematical description, the weak formulation, and the parameters for the PNP equations are given in the next sections.

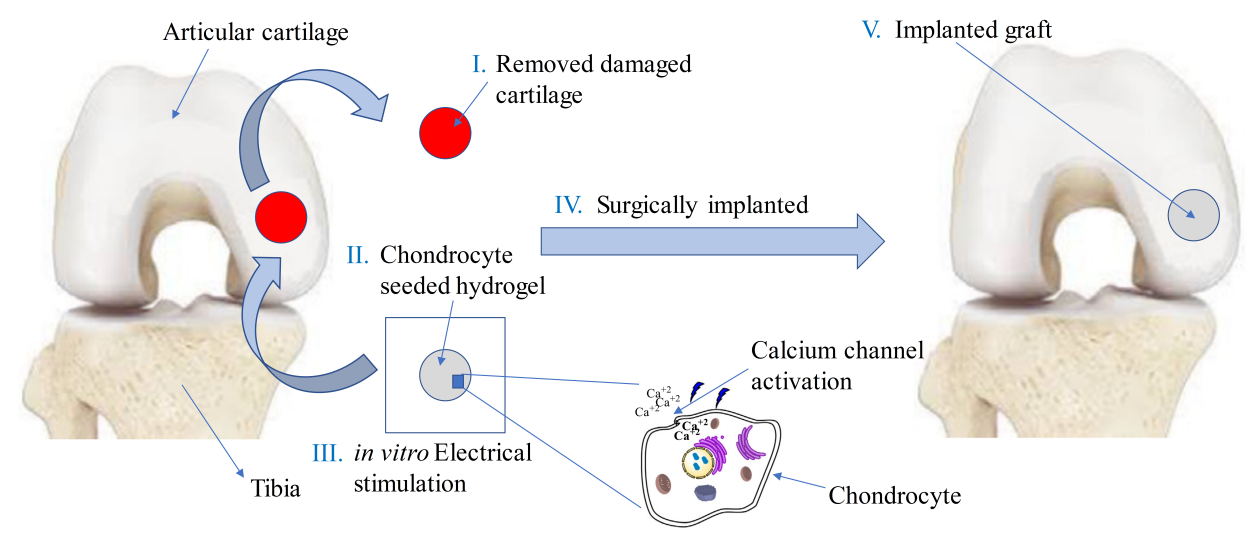

Figure 1. Various steps involved in tissue engineering of knee articular cartilage using electrical stimulation by replacing defect site with chondrocyte-seeded hydrogel (adapted from [11]).

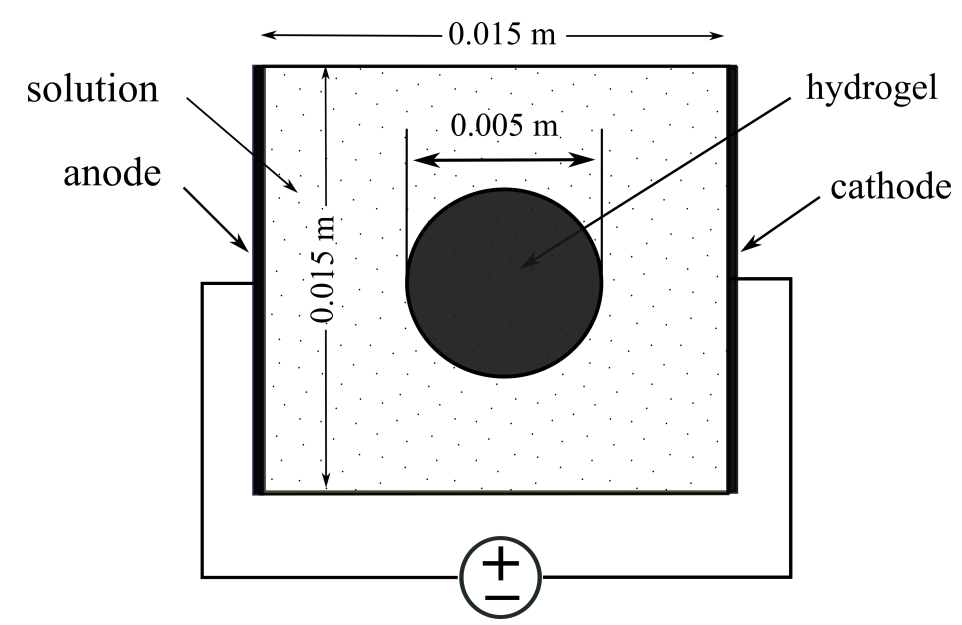

Figure 2. Hydrogel sample immersed in $\mathrm{NaCl}$ bath solution under externally applied electric field. 


\section{Materials and Methods}

Several mathematical formulations were proposed to simulate the electrochemical behavior of electroactive hydrogels immersed in a solution bath. Based on Flory's theory [71] and the Donnan equilibrium [72], Shiga et al. [73], and Doi et al. [74] developed models to investigate the hydrogel behavior under an applied electric field. Grimshaw et al. [75] presented a macroscopic continuum theory to explain the dynamic response of hydrogels to electric stimulation. However, these models were not able to precisely simulate the behavior of electroactive hydrogels.

A significant amount of the literature to simulate the electroactive behavior of hydrogels originates from the studies of hydrogel-like biological tissue like articular cartilage. It includes the triphasic theory of Lai et al. [76] and te multiphasic theory of Gu et al. [77], which are based on the classical biphasic theory of Mow et al. [78]. However, these theories are not suitable in simulating electrochemical phenomena in hydrogels, such as ion diffusion and the effect of fixed-charge density on ionic-concentration distribution. Zhou et al. [79] extended the triphasic model to describe the behavior of electroactive hydrogels immersed in the solution, but the computational domain only covered the hydrogel, which limited its applicability.

Based on multiphasic mixture theory, Li et al. [80] proposed a comprehensive model to describe the coupling effects and the multiphasic interactions in the electroactive hydrogels. Similarly, the transport model of polyelectrolyte hydrogels was developed by Wallmersperger et al. [81,82]. Both these models were similar as they consisted of nonlinear coupled PNP equations to describe diffusive ionic species and electric potential, but differed in coupling the electrochemical response to the mechanical equilibrium equation. Since we are only concerned with the electrochemical behavior, either of these two models could be used for result comparison.

In the current study, the model proposed by Wallmersperger et al. [81] was adapted to carry out finite-element simulations. The geometry of the problem is shown in Figure 2, where a square hydrogel sample was first considered for validation instead of the circular hydrogel sample. The model comprised two coupled nonlinear differential equations, i.e., Poisson and Nernst-Planck equations, described below. The PNP equations present several difficulties when computing approximate solutions. It is a strongly coupled system of $n+1$ nonlinear equations, so computational efficiency plays a critical role in the implementation of the numerical solution, where $n$ is the number of mobile ion species.

To date, the PNP model for hydrogels has been simulated using custom programs implemented in individual workgroups [80] that are not generally publicly available. Few of them have also been implemented using commercial software [83]. These models have mostly been implemented for one-dimensional (1D) cases, and a small number of them for the two-dimensional (2D) cases. None of the models has been implemented so far using any open-source software and for the electrical-stimulation response of the hydrogels in context of cartilage-tissue engineering. We have therefore carried out the simulations of electroactive hydrogels for cartilage-tissue engineering using open-source numerical software FEniCS [84].

As the geometry considered here is relatively simple, the geometry creation, meshing, and solving the variational problem could all be done using FEniCS, and then visualizing the results using Paraview [85]. For physiologically more complicated geometries, a more comprehensive open-source simulation workflow was implemented as well, which consisted of SALOME (www.salome-platform. org) for geometry creation, Gmsh [86] for meshing, the solution of variational problem using FEniCS, and then result visualization using Paraview. The complete open-source workflow is shown in Figure 3. The results presented here are the same by using either of the two simulation workflows discussed here. The models and the Python scripts used in this study are available in an online repository (https://github.com/arfarooqi/Electro-active-hydrogels). 


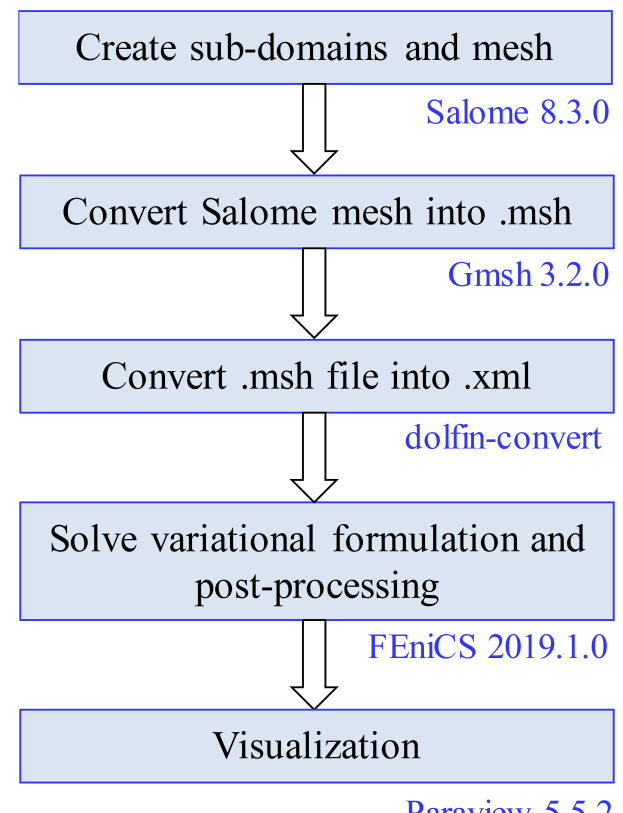

Figure 3. Proposed open-source simulation workflow.

\subsection{Poisson Equation}

The Poisson equation for the electric potential is derived from Gauss's law, which states that

$$
\nabla \cdot \mathbf{D}=\rho
$$

where $\mathbf{D}$ and $\rho$ are the electric flux density and the charge density, respectively, which are defined as

$$
\begin{gathered}
\mathbf{D}=\varepsilon_{r} \varepsilon_{o} \mathbf{E}=-\varepsilon_{r} \varepsilon_{o} \nabla \psi \\
\nabla \cdot\left(-\varepsilon_{r} \varepsilon_{o} \nabla \psi\right)=\rho
\end{gathered}
$$

where $\varepsilon_{r}$ is the relative permittivity of the surrounding medium, $\varepsilon_{o}$ is the vacuum permittivity or dielectric constant, and $\psi$ is the electric potential. As the electric field may be assumed to be curlfree, i.e., the time derivative of the magnetic flux density is negligibly small, we could use a scalar potential as a solution approach [87]. Charge density $\rho$ was related to the mobile and fixed ion concentrations as

$$
\rho=F\left(\sum_{k=1}^{n} z^{k} c^{k}+z^{f} c^{f}\right)
$$

where $F$ is Faraday's constant, $c^{k}$ represent the ionic concentrations with valence $z^{k}$, and $c^{f}$ is the concentration of fixed ionic species with valence $z^{f}$. From Equations (1) and (2), we get Poisson's equation as

$$
\nabla^{2} \psi+\frac{F}{\varepsilon_{r} \varepsilon_{o}}\left(\sum_{k=1}^{n} z^{k} c^{k}+z^{f} c^{f}\right)=0 .
$$

Applying homogeneous Neumann boundary conditions at the top and bottom surface of the solution bath, the weak formulation of Poisson's equation is [88]

$$
\int_{\Omega} \nabla \psi \cdot \nabla v_{\psi} d x=\frac{F}{\varepsilon_{r} \varepsilon_{o}} \int_{\Omega}\left(z^{+} c^{+}+z^{-} c^{-}+z^{f} c^{f}\right) v_{\psi} d x
$$


where two ionic species were considered, i.e., cation ' + ' and anion ' $-{ }^{\prime}, v_{\psi}$ is the test function, and $d x$ denotes the differential element for integration over the domain $\Omega$. Here, integration by parts is used and the test function is assumed to vanish on the boundary of the domain $\Omega$.

\subsection{Nernst-Planck Equation}

Total flux $\mathbf{J}^{k}$ of ion $k$ is composed of three components: diffusion flux $\mathbf{J}_{\text {diff }}^{k}$ caused by the chemical potential gradient of ions, electric transference $\mathbf{J}_{\text {elect }}^{k}$ caused by the electrical potential gradient, and transfer $\mathbf{J}_{\mathrm{conv}}^{k}$ caused by the convection. They are written as [89]

$$
\begin{aligned}
\mathbf{J}_{\text {diff }}^{k} & =-D^{k} c^{k} \nabla \mu^{k}, \\
\mathbf{J}_{\text {elect }}^{k} & =-z^{k} \mu^{k} c^{k} \nabla \psi, \\
\mathbf{J}_{\text {conv }}^{k} & =c^{k} v .
\end{aligned}
$$

where $D^{k}$ is the diffusivity of the $k$ th ionic species, $\mu^{k}$ is the ionic mobility, and $v$ is the area-averaged fluid velocity through the hydrogel, relative to the hydrogel's polymer network. If the effect of the activity coefficient is explicitly taken into account, the diffusion flux becomes

$$
\mathbf{J}_{\text {diff }}^{k}=-D^{k}\left(\nabla c^{k}+c^{k} \nabla \ln f^{k}\right)
$$

where $f^{k}$ is the chemical-activity coefficient of the $k$ th species. Total flux $\mathbf{J}^{k}$ can now be written as

$$
\mathbf{J}^{k}=-\left(D^{k} \nabla c^{k}+D^{k} c^{k} \nabla \ln f^{k}+z^{k} \mu^{k} c^{k} \nabla \psi\right)+c^{k} \nu .
$$

The continuity equation that governs the flux of ionic species throughout the hydrogel and the surrounding solution is given as

$$
\frac{\partial c^{k}}{\partial t}+\nabla \cdot \mathbf{J}^{k}=0
$$

The first term in Equation (12) represents the change of concentrations with time, while the second term is the combination of the following four contributive terms: the migrative term due to a gradient in the electric potential, the diffusive term resulting from concentration differences, the convective term due to an applied velocity of the solvent, and the source term due to chemical reactions inside the gel-solution domain or at the electrodes.

In Equation (11), it was then assumed that no chemical reactions occurred and convection was neglected. Then, continuity Equation (12) becomes [90-92]

$$
\frac{\partial c^{k}}{\partial t}=\nabla \cdot\left(D^{k} \nabla c^{k}+z^{k} \mu^{k} c^{k} \nabla \psi\right)
$$

Next, mobility $\mu^{k}$ could be determined from the Nernst-Einstein relationship, which relates diffusivity to ionic mobility [93],

$$
\mu^{k}=\frac{D^{k} F}{R T} .
$$

where $R$ is the universal gas constant, and $T$ is the absolute temperature. So, Equation (13) becomes

$$
\frac{\partial c^{k}}{\partial t}=\nabla \cdot\left(D^{k} \nabla c^{k}+\frac{z^{k} F}{R T} D^{k} c^{k} \nabla \psi\right) .
$$

Now, the weak formulation of Equation (15) considering two ionic species is obtained by multiplying with a test function $v_{k}$ and integrating over domain $\Omega$, 


$$
\int_{\Omega} \frac{\partial c^{k}}{\partial t} v_{k} d x=D^{k} \int_{\Omega} \nabla c^{k} \cdot \nabla v_{k} d x+D^{k} \frac{z^{k} F}{R T} \int_{\Omega} c^{k} \nabla \psi \cdot \nabla v_{k} d x, \quad(k=+,-) .
$$

The time derivative can be approximated by using backward (or implicit) Euler difference method [94]

$$
\frac{\partial c^{k}}{\partial t} \approx \frac{c_{i+1}^{k}-c_{i}^{k}}{\Delta t}
$$

where $\Delta t$ is the time-step parameter, and $c_{i+1}^{k}$ and $c_{i}^{k}$ represent the concentration of ions for the new and the previous time step, respectively. Using the above notation, Equation (16) was rewritten as

$$
\int_{\Omega} c_{i+1}^{k} v_{k} d x-\int_{\Omega} c_{i}^{k} v_{k} d x=\Delta t D^{k} \int_{\Omega} \nabla c^{k} \cdot \nabla v_{k} d x+\Delta t D^{k} \frac{z^{k} F}{R T} \int_{\Omega} c^{k} \nabla \psi \cdot \nabla v_{k} d x, \quad(k=+,-) .
$$

For the numerical solution of the PNP equations, mixed-function space [95] consisting of three scalar functions, i.e., anion, cation, and electric potential was used with Lagrange elements [96,97] of Order 2.

\section{Results and Discussion}

\subsection{Chemical Stimulation}

Initially, the hydrogel was taken out of a solution bath with concentration of $2 \mathrm{mM}$ and put into another with concentration of $1 \mathrm{mM}$. The concentration of bound anionic groups in the hydrogel was $2 \mathrm{mM}$ and the boundary conditions for the ions at the solution boundary were set to $1 \mathrm{mM}$. Biological tissue like cartilage and hydrogels exhibited the phenomenon of swelling. It was caused by electric charges fixed to the porous solid. They attracted free ions of the opposite charge, present in the fluid. Fluid flow took place between the hydrogels and the salt solution until equilibrium was reached. The Donnan equilibrium concentration of ions in the hydrogel was calculated using [98,99]

$$
\begin{aligned}
& c_{\text {gel }}^{+}=\frac{1}{2}\left(-c^{f}+\sqrt{\left[c^{f}\right]^{2}+4\left[c_{\mathrm{sol}}^{-}\right]^{2}}\right) \\
& c_{\text {gel }}^{-}=\frac{1}{2}\left(c^{f}+\sqrt{\left[c^{f}\right]^{2}+4\left[c_{\mathrm{sol}}^{-}\right]^{2}}\right) .
\end{aligned}
$$

The corresponding Donnan potential created due to the concentration difference inside and outside the hydrogel could be found either in terms of cation or anion concentrations [100-102],

$$
\Delta \phi=\frac{R T}{z^{+} F} \ln \left(\frac{c_{\mathrm{gel}}^{+}}{c_{\mathrm{sol}}^{+}}\right) \quad \text { or } \quad \Delta \phi=\frac{R T}{z^{-} F} \ln \left(\frac{c_{\mathrm{gel}}^{-}}{c_{\mathrm{sol}}^{-}}\right) .
$$

Using Equation (19), the concentration of anions and cations in the hydrogel due to chemical stimulation are 0.4142 and $2.4142 \mathrm{mM}$, respectively. Similarly, from Equation (20), the value of the Donnan potential was $-22.252 \mathrm{mV}$. Now, the steady-state numerical solution for the chemical stimulation was performed using Equations (6) and (18) considering two ionic species with the concentration of $1 \mathrm{mM}$ for both species at the solution boundaries. For the chemical stimulation, an externally applied electric field was set to zero at the solution boundaries. The parameters used for the numerical simulation are listed in Table 1, and 1D results of the chemical stimulation are shown in Figures 4-6, which were the same as by using Donnan theory. These results were also in agreement with the numerical results of Wallmersperger et al. [81]. 
(a)

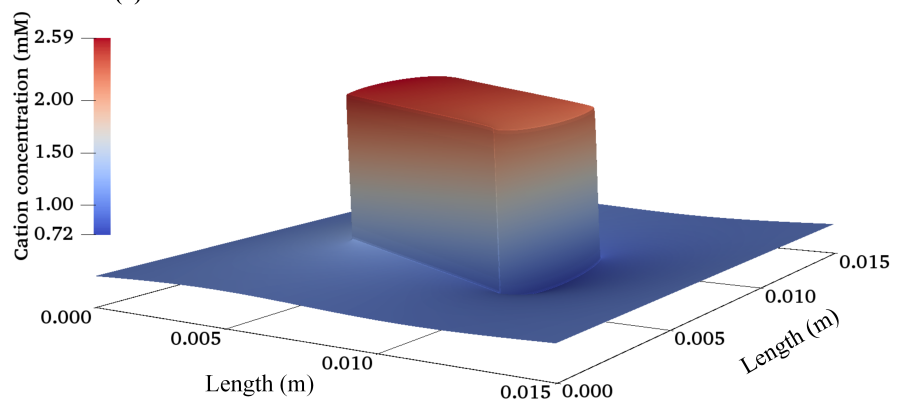

(b)

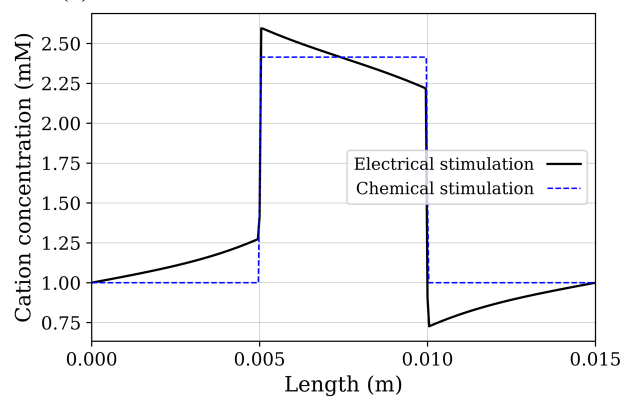

Figure 4. Cation concentration: (a) 2D electrical stimulation, (b) comparison of chemical and electrical stimulation versus $x$-position at $y=0.0075 \mathrm{~m}$.

(a)

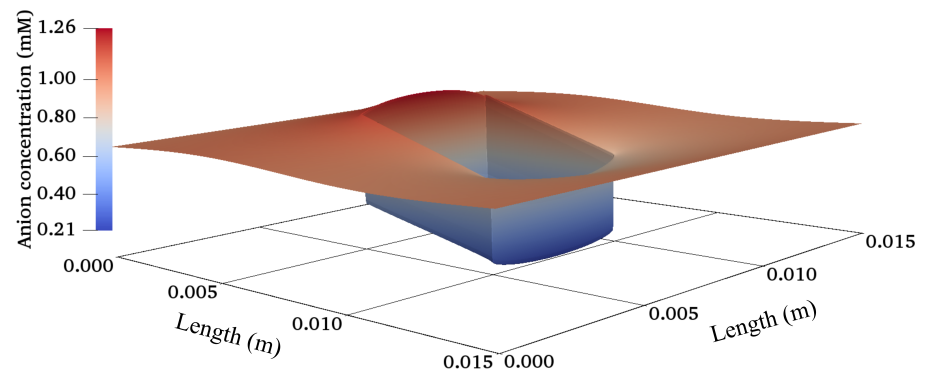

(b)

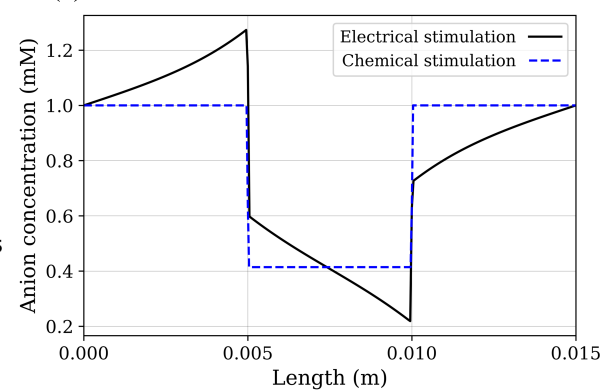

Figure 5. Anion concentration: (a) 2D electrical stimulation, (b) comparison of chemical and electrical stimulation versus $x$-position at $y=0.0075 \mathrm{~m}$.

(a)

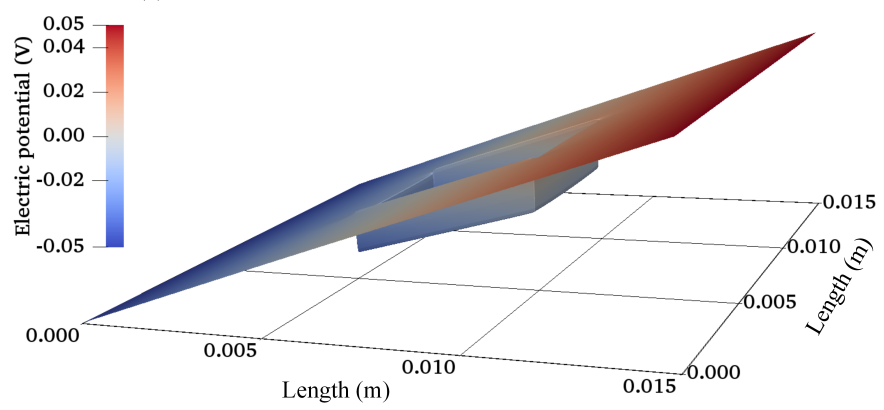

(b)

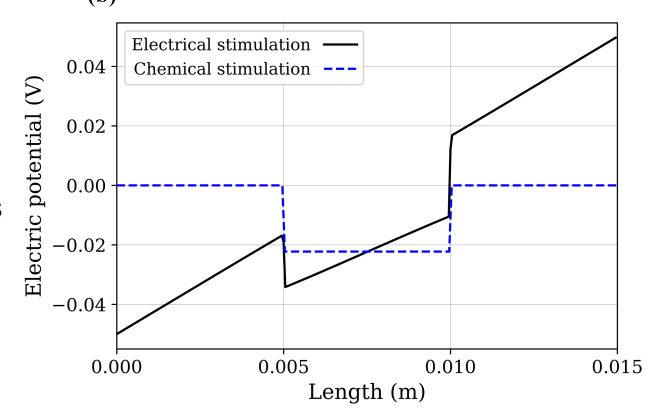

Figure 6. Electric potential: (a) 2D electrical stimulation, (b) comparison of chemical and electrical stimulation versus $x$-position at $y=0.0075 \mathrm{~m}$.

Table 1. Simulation parameters used for simulations [81].

\begin{tabular}{ll}
\hline Parameter & Value \\
\hline Cation valence $z^{+}$ & 1.0 \\
Anion valence $z^{-}$ & -1.0 \\
Bound charge valence $z^{f}$ & -1.0 \\
Ion mobility $\mu^{k}$ & $3.9607 \times 10^{-6} \mathrm{~m}^{2} \mathrm{~s}^{-1} \mathrm{~V}^{-1}$ \\
Ion diffusion coefficient $D^{k}$ & $1.0 \times 10^{-7} \mathrm{~m}^{2} \mathrm{~s}^{-1}$ \\
Faraday constant $F$ & $9.6487 \mathrm{C} \mathrm{mol}^{-1}$ \\
Temperature $T$ & $293 \mathrm{~K}$ \\
Gas constant $R$ & $8.3143 \mathrm{~J} \mathrm{~mol}^{-1} \mathrm{~K}^{-1}$ \\
Vacuum permittivity $\epsilon_{o}$ & $8.854 \times 10^{-12} \mathrm{As} \mathrm{V}^{-1} \mathrm{~m}^{-1}$ \\
Relatively permittivity $\epsilon_{r}$ & 100.0 \\
\hline
\end{tabular}




\subsection{Electrical Stimulation}

For the electrical stimulation, Equations (6) and (18) were again solved numerically for two ionic species using FEniCS with the parameters listed in Table 1. The convective flux was assumed to be zero and no chemical conversion was considered in the equations. The values obtained due to the chemical stimulation were taken as initial conditions for the electrical-stimulation problem, and an external electric potential of $50 \mathrm{mV}$ was applied at the solution boundaries. To achieve the rapid convergence of the solution, local mesh refinement was used, which extended $0.002 \mathrm{~m}$ on both sides of the hydrogel-solution interface.

As the electrical stimulation was applied to the bath solution in which the hydrogel was immersed, mobile ions were redistributed in both the hydrogel and the surrounding solution. Due to the fixed-charge groups bound to the cross-linked macromolecular chains of the hydrogel, the diffusion gave rise to the ionic-concentration differences between the interior hydrogel and the exterior bath solution. The graphs for anion, cation, and electric potential distribution are shown in Figures 4-6, where $24,668,895$ degrees of freedom (DoFs) were used. The $1 \mathrm{D}$ graphs for the same quantities extracted from the 2D plots at positions $x$ and $y=0.0075 \mathrm{~m}$ are also shown in the same figures. These results are in agreement to the numerical results of Wallmersperger et al. [81], and in qualitative agreement to the experiment results of Gülch et al. [103].

After validation, the finite-element model was extended for a 2D circular specimen (approximation of a 3D cylindrical sample) immersed in solution as used in cartilage-tissue engineering [104] and shown in Figure 1. Figures 7-9 show the graphs of the anion, cation, and electric potential distribution in the solution and in the hydrogel scaffold in steady state. Because of the presence of fixed-charge ions in the hydrogel, there was a sharp change in electric potential and in the concentrations of anions and cations to satisfy the electroneutrality condition. In comparison to the initial conditions, the concentrations of cations and anions were slightly higher in the hydrogel on the cathode side as compared to the anode side. Similarly, ion concentrations in the solution near the hydrogel-solution interface increased at the cathode side and decreased at the anode side. From these figures, it can be concluded that the ion concentrations and electric potential in the hydrogel sample could be optimized as the requirement by varying the different quantities. The computation time was $\sim 58 \mathrm{~min}$ with 22,264,695 DoFs on a workstation with 256 GB RAM, Intel(R) Xeon(R) CPU E5-2687W v4 @ 3.00 GHz.

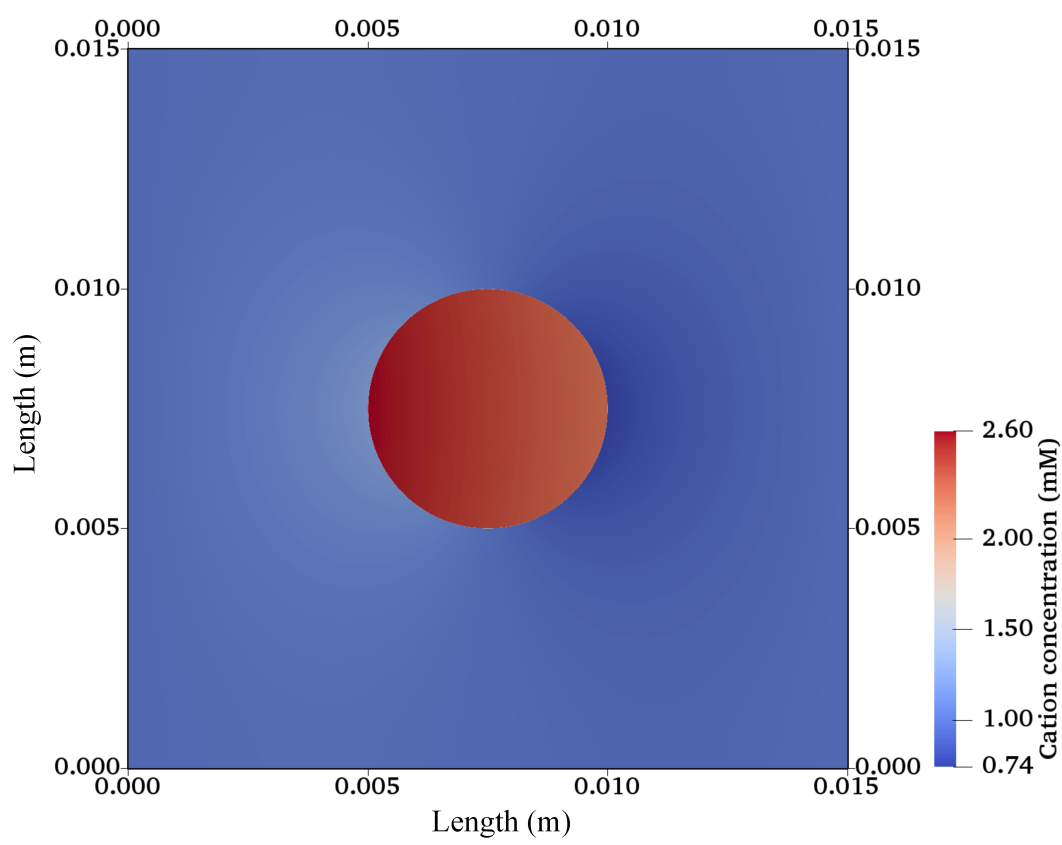

Figure 7. Cation-concentration profile for a hydrogel scaffold immersed in solution. 


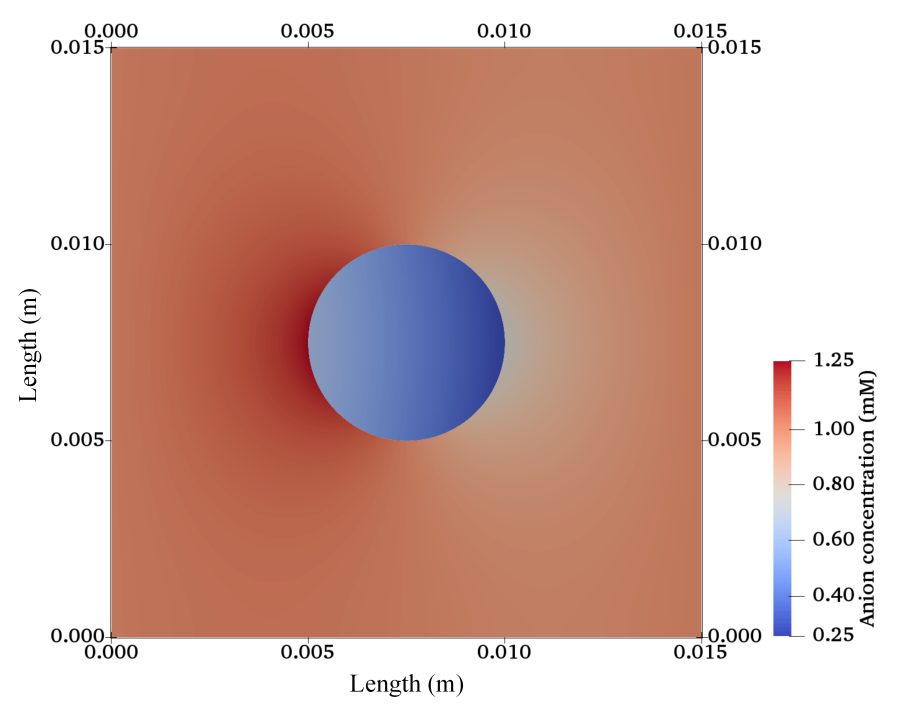

Figure 8. Anion concentration profile for a hydrogel scaffold immersed in solution.

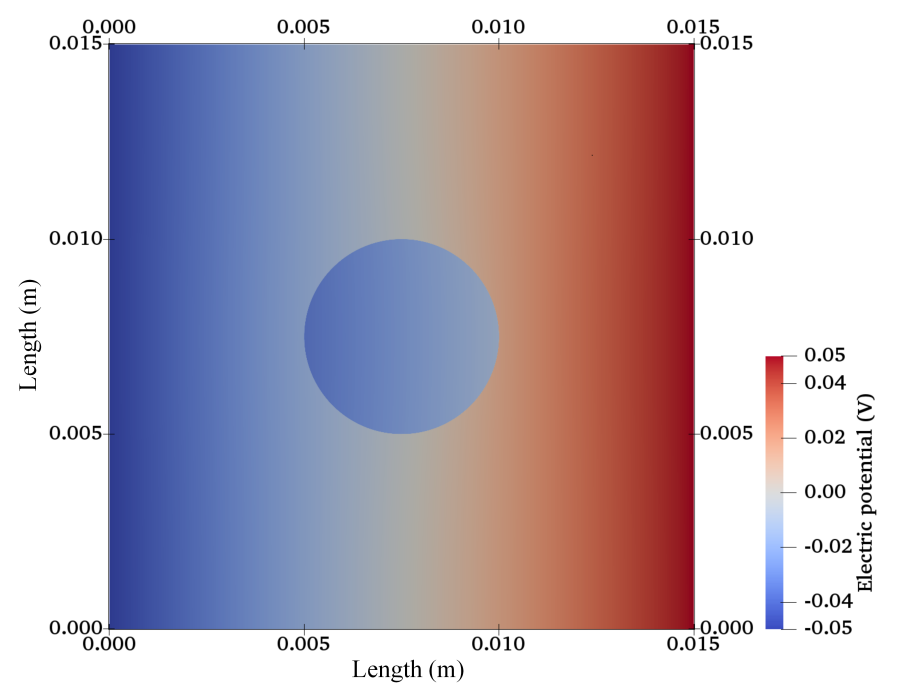

Figure 9. Electric potential distribution for a hydrogel scaffold immersed in solution.

Transient simulations for variations of the ionic concentration and electric potential are also presented in Figure 10. It was observed that, at initial time $t=0$, the distributions of ionic concentrations in whole computational domain are symmetric, same as from the chemical stimulation without external electric field. As time increased, the diffusive ions redistributed continuously in both the hydrogel and the $1 \mathrm{mM} \mathrm{NaCl}$ solution, and the ionic-concentration differences near the hydrogel-solution interfaces became increasingly larger. Ionic diffusion and convection reached the equilibrium state after a specific time, which was dependent on various parameters and conditions, including the electric field, fixed charge density, and $\mathrm{NaCl}$ solution concentration. Thus, the concentration of ions and the electric potential in the hydrogel sample could be optimized at various time intervals. For the current case, the steady-state solution for all variables was obtained at around $800 \mathrm{~s}$, after which no further change in the ion concentrations and electric potential occurred. These results follow the same trend as observed by Wallmersperger et al. [81].

Our model still has some limitations that we briefly mention here. The presented numerical method does not explicitly include cells and is thus not capable of estimating an effect on chondrocytes. The numerical method in its current state is also rather expensive and needs tuning on the numerical side. A quantitative comparison to experiment data cannot yet be established since some material parameters like ion mobility and diffusion coefficient have not yet been experimentally measured. 
(a)

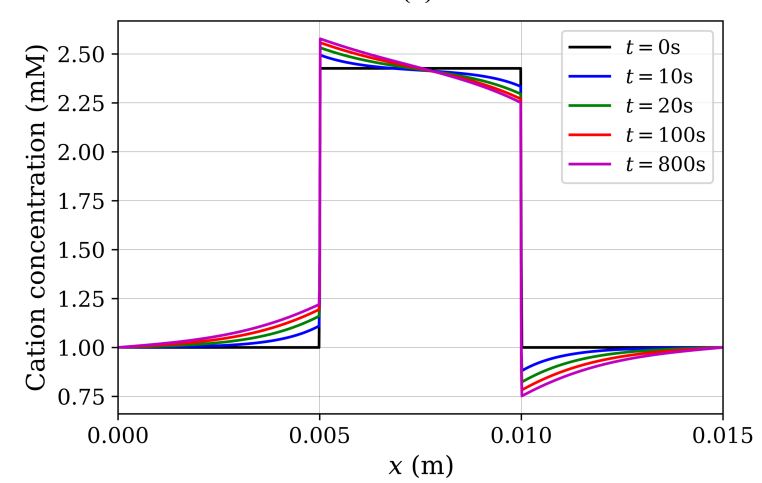

(b)

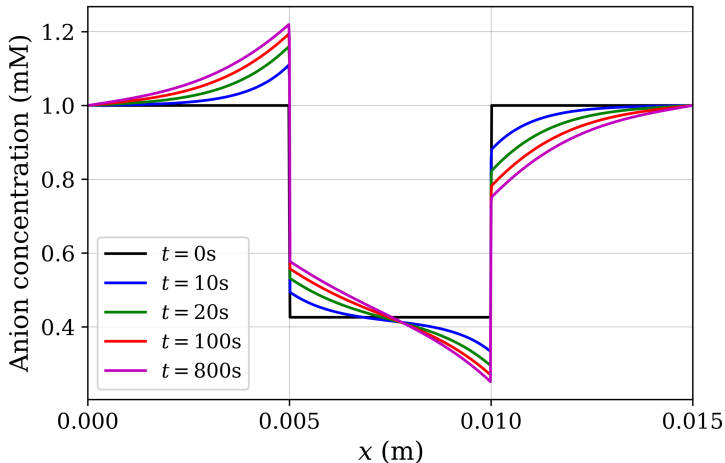

(c)

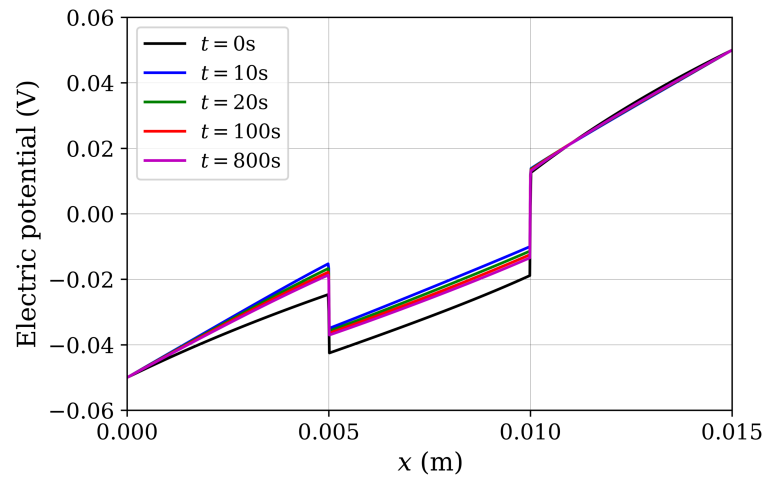

Figure 10. Transient variation of quantities for a hydrogel scaffold immersed in solution: (a) cation concentration, (b) anion concentration, (c) electric potential.

\section{Conclusions}

In this paper, reported research studies to date were summarized using either the direct or indirect electrical stimulation of chondrocytes, cartilage tissue, and cell-seeded hydrogel scaffolds. It is evident that both types of electrical stimulation could be beneficial for cartilage-tissue engineering approaches. However, a complete understanding of the transduction pathways and interaction mechanisms due to electrical stimulation is still lacking for designing an optimized electrical-stimulation protocol.

The development of efficient reproducible computational models is crucial to simulate biological tissue for the better and improved understanding of physiological interactions and therapeutic approaches. On the other hand, modeling the behavior of a hydrogel immersed in a solution bath is challenging due to highly coupled nonlinear PDEs. To date, the behavior of electroactive hydrogels immersed in a solution has been simulated using custom programs implemented in individual laboratories that are not publicly available. A few of the models have also been implemented using commercial softwares, but mostly for 1D cases. None of the models have been implemented so far using any open-source software and for the electrical-stimulation response of the hydrogels in the context of cartilage-tissue engineering. Thus, a 2D open-source computational model has been proposed to study the effect of electrical stimulation on a hydrogel scaffold for cartilage-tissue engineering at the mesoscale. The proposed model was verified against results available in the literature and then extended for a circular geometry by solving the PNP equations using FEniCS. This model can further be extended to study cellular interactions at a microscale. Hence, the current study is a step forward in providing augmented computational models for cartilage-tissue engineering in combination with electrical stimulation. 
Author Contributions: Conceptualization, A.R.F., J.Z., R.B. and U.v.R.; formal analysis, A.R.F.; software, A.R.F. and J.Z.; validation, A.R.F. and J.Z.; funding acquisition, R.B. and U.v.R.; investigation, A.R.F.; methodology, A.R.F., J.Z., R.B. and U.v.R.; resources, U.v.R.; supervision, R.B. and U.v.R.; visualization, A.R.F.; writing-original draft, A.R.F.; writing—review and editing, A.R.F., J.Z., R.B. and U.v.R.

Funding: The work was funded by the DAAD (German Academic Exchange Service) and the Higher Education Commission, Pakistan through a doctoral scholarship, and is supported by the German Science Foundation (DFG) in the scope of the CRC 1270 "Electrically Active Implants" ELAINE.

Acknowledgments: We thank Thomas Distler, Department of Material Science and Engineering, Friedrich-Alexander University of Erlangen-Nuremberg for his critical reading of the manuscript and valuable comments.

Conflicts of Interest: The authors declare no conflict of interest. The authors alone are responsible for the content and writing of the paper.

\section{References}

1. Mow, V.C.; Ratcliffe, A.; Robin Poole, A. Cartilage and diarthrodial joints as paradigms for hierarchical materials and structures. Biomaterials 1992, 13, 67-97. [CrossRef]

2. Jahr, H.; Matta, C.; Mobasheri, A. Physicochemical and biomechanical stimuli in cell-based articular cartilage repair. Curr. Rheumatol. Rep. 2015, 17, 22. [CrossRef] [PubMed]

3. De Mattei, M.; Pellati, A.; Pasello, M.; Ongaro, A.; Setti, S.; Massari, L.; Gemmati, D.; Caruso, A. Effects of physical stimulation with electromagnetic field and insulin growth factor-I treatment on proteoglycan synthesis of bovine articular cartilage. Osteoarthr. Cartil. 2004, 12, 793-800. [CrossRef] [PubMed]

4. Mow, V.C.; Wang, C.C.; Hung, C.T. The extracellular matrix, interstitial fluid and ions as a mechanical signal transducer in articular cartilage. Osteoarthr. Cartil. 1999, 7, 41-58. [CrossRef] [PubMed]

5. Servin-Vences, M.R.; Richardson, J.; Lewin, G.R.; Poole, K. Mechanoelectrical transduction in chondrocytes. Clin. Exp. Pharmacol. Physiol. 2018, 45, 481-488. [CrossRef] [PubMed]

6. Cohen, N.P.; Foster, R.J.; Mow, V.C. Composition and Dynamics of Articular Cartilage: Structure, Function, and Maintaining Healthy State. J. Orthop. Sport. Phys. Ther. 1998, 28, 203-215. [CrossRef] [PubMed]

7. Fox, A.J.S.; Bedi, A.; Rodeo, S.A. The basic science of articular cartilage: Structure, composition, and function. Sports Health 2009, 1, 461-468. [CrossRef]

8. Korhonen, R.K.; Julkunen, P.; Jurvelin, J.S.; Saarakkala, S. Structural and compositional changes in peri- and extracellular matrix of osteoarthritic cartilage modulate chondrocyte morphology. Cell. Mol. Bioeng. 2011, 4, 484-494. [CrossRef]

9. Lee, J.H.; Kim, H.W. Emerging properties of hydrogels in tissue engineering. J. Tissue Eng. 2018, 9, 1-4. [CrossRef]

10. Kwon, H.J. Tissue Engineering of Muscles and Cartilages Using Polyelectrolyte Hydrogels. Adv. Mater. Sci. Eng. 2014, 2014, 154071. [CrossRef]

11. More, N.; Kapusetti, G. Piezoelectric material-A promising approach for bone and cartilage regeneration. Med. Hypotheses 2017, 108, 10-16. [CrossRef] [PubMed]

12. Chuang, E.Y.; Chiang, C.W.; Wong, P.C.; Chen, C.H. Hydrogels for the application of articular cartilage tissue Engineering: A review of hydrogels. Adv. Mater. Sci. Eng. 2018, 2018, 4368910. [CrossRef]

13. Mohammadi, A.; Hill, R.J. Steady electrical and micro-rheological response functions for uncharged colloidal inclusions in polyelectrolyte hydrogels. Proc. R. Soc. A 2010, 466, 213-235. [CrossRef]

14. Mohammadi, A. Electrokinetic Mixing and Displacement of Charged Droplets in Hydrogels. Transp. Porous Media 2014, 104, 469-499. [CrossRef]

15. Ning, C.; Zhou, Z.; Tan, G.; Zhu, Y.; Mao, C. Electroactive polymers for tissue regeneration: Developments and perspectives. Prog. Polym. Sci. 2018, 81, 144-162. [CrossRef] [PubMed]

16. Spiller, K.L.; Maher, S.A.; Lowman, A.M. Hydrogels for the Repair of Articular Cartilage Defects. Tissue Eng. Part B Rev. 2011, 17, 281-299. [CrossRef]

17. Salinas, E.Y.; Hu, J.C.; Athanasiou, K.A. A Guide for Using Mechanical Stimulation to Enhance Tissue-Engineered Articular Cartilage Properties. Tissue Eng. Part B Rev. 2018, 24, 345-358. [CrossRef]

18. Farooqi, A.R.; Bader, R.; van Rienen, U. Numerical Study on Electromechanics in Cartilage Tissue with Respect to Its Electrical Properties. Tissue Eng. Part B Rev. 2019, 25, 152-166. [CrossRef] [PubMed] 
19. Brady, M.A.; Waldman, S.D.; Ethier, C.R. The Application of Multiple Biophysical Cues to Engineer Functional Neocartilage for Treatment of Osteoarthritis. Part II: Signal Transduction. Tissue Eng. Part B Rev. 2015, 21, 20-33. [CrossRef] [PubMed]

20. Iwasa, K.; Reddi, A.H. Pulsed Electromagnetic Fields and Tissue Engineering of the Joints. Tissue Eng. Part B Rev. 2018, 24, 144-154. [CrossRef]

21. Fini, M.; Pagani, S.; Giavaresi, G.; De Mattei, M.; Ongaro, A.; Varani, K.; Vincenzi, F.; Massari, L.; Cadossi, M. Functional tissue engineering in articular cartilage repair: Is there a role for electromagnetic biophysical stimulation? Tissue Eng. Part B Rev. 2013, 19, 353-367. [CrossRef] [PubMed]

22. Brady, M.A.; Waldman, S.D.; Ethier, C.R. The application of multiple biophysical cues to engineer functional neo-cartilage for treatment of osteoarthritis. Part I: Cellular response. Tissue Eng. Part B Rev. 2015, 21, 1-19. [CrossRef] [PubMed]

23. Balint, R.; Cassidy, N.J.; Cartmell, S.H. Electrical stimulation: A novel tool for tissue engineering. Tissue Eng. Part B Rev. 2013, 19, 48-57. [CrossRef] [PubMed]

24. Thrivikraman, G.; Boda, S.; Basu, B. Unraveling the mechanistic effects of electric field stimulation towards directing stem cell fate and function: A tissue engineering perspective. Biomaterials 2018, 150, 60-86. [CrossRef] [PubMed]

25. McElhaney, J.H.; Stalnaker, R.; Bullard, R. Electric fields and bone loss of disuse. J. Biomech. 1968, 1, 47-52. [CrossRef]

26. Merrill, D.R.; Bikson, M.; Jefferys, J.G. Electrical stimulation of excitable tissue: Design of efficacious and safe protocols. J. Neurosci. Methods 2005, 141, 171-198. [CrossRef] [PubMed]

27. Szasz, N. Electric Field Regulation of Chondrocyte Proliferation, Biosynthesis, and Cellular Signaling. Ph.D. Thesis, Massachusetts Institute of Technology, Cambridge, MA, USA, 2003.

28. Brighton, C.T.; Wang, W.; Seldes, R.; Zhang, G.; Pollack, S.R. Signal transduction in electrically stimulated bone cells. J. Bone Jt. Surg. 2001, 83, 1514-1523. [CrossRef]

29. Vega, S.L.; Kwon, M.Y.; Burdick, J.A. Recent advances in hydrogels for cartilage tissue engineering. Eur. Cells Mater. 2017, 33, 59-75. [CrossRef]

30. Yang, J.; Zhang, Y.S.; Yue, K.; Khademhosseini, A. Cell-laden hydrogels for osteochondral and cartilage tissue engineering. Acta Biomater. 2017, 57, 1-25. [CrossRef]

31. Sánchez-Téllez, D.A.; Téllez-Jurado, L.; Rodríguez-Lorenzo, L.M. Hydrogels for cartilage regeneration, from polysaccharides to hybrids. Polymers (Basel) 2017, 9, 671. [CrossRef]

32. Yuk, H.; Lu, B.; Zhao, X. Hydrogel bioelectronics. Chem. Soc. Rev. 2019, 48, 1642-1667. [CrossRef] [PubMed]

33. Baker, B.; Spadaro, J.; Marino, A.; Backer, R.O. Electrical stimulation of articular cartilage regeneration. Ann. N. Y. Acad. Sci. 1974, 238, 491-499. [CrossRef] [PubMed]

34. Baker, B.; Becker, R.O.; Spadaro, J. A study of electrochemical enhancement of articular cartilage repair. Clin. Orthop. Relat. Res. 1974, 102, 251-267. [CrossRef] [PubMed]

35. Lippiello, L.; Chakkalakal, D.; Connolly, J.F. Pulsing direct current-induced repair of articular cartilage in rabbit osteochondral defects. J. Orthop. Res. 1990, 8, 266-275. [CrossRef] [PubMed]

36. Frank, E.H.; Grodzinsky, A.J. Cartilage electromechanics-I. Electrokinetic transduction and the effects of electrolyte $\mathrm{pH}$ and ionic strength. J. Biomech. 1987, 20, 615-627. [CrossRef]

37. Frank, E.H.; Grodzinsky, A.J. Cartilage electromechanics-II. A continuum model of cartilage electrokinetics and correlation with experiments. J. Biomech. 1987, 20, 629-639. [CrossRef]

38. Berkenblit, S.I.; Frank, E.H.; Salant, E.P.; Grodzinsky, A.J. Nondestructive detection of cartilage degeneration using electromechanical surface spectroscopy. J. Biomech. Eng. 1994, 116, 384-392. [CrossRef]

39. Akkin, T.; Davé, D.P.; Youn, J.I.; Telenkov, S.A.; Rylander, H.G.; Milner, T.E. Imaging Tissue Response to Electrical and Photothermal Stimulation with Nanometer Sensitivity. Lasers Surg. Med. 2003, 33, $219-225$. [CrossRef]

40. Youn, J.I.; Akkin, T.; Milner, T.E. Electrokinetic measurement of cartilage using differential phase optical coherence tomography. Physiol. Meas. 2004, 25, 85-95. [CrossRef]

41. Gray, M.L. Physical Regulation of Epiphysical Cartilage Biosynthesis: Responses to Electrical, Mechanical and Chemical Signals. Ph.D. Thesis, Massachusetts Institute of Technology, Cambridge, MA, USA, 1986.

42. MacGinitie, L.A. Electrical and Thermal Modulation of Protein Synthesis in Cartilage: A Model for Field Effects on Biological Tissues. Ph.D. Thesis, Massachusetts Institute of Technology, Cambridge, MA, USA, 1987. 
43. MacGinitie, L.A.; Grodzinsky, A.J.; Frank, E.H.; Gluzband, Y.A. Frequency and amplitude dependence of electric field interactions: Electrokinetics and biosynthesis. In Mechanistic Approaches to Interactions of Electric and Electromagnetic Fields with Living Systems; Blank, M., Findl, E., Eds.; Springer: Boston, MA, USA, 1987; pp. 133-149. [CrossRef]

44. MacGinitie, L.A.; Gluzband, Y.A.; Grodzinsky, A.J. Electric Field Stimulation Can Increase Protein Synthesis in Articular Cartilage Explants. J. Orthop. Res. 1994, 12, 151-160. [CrossRef]

45. Nogami, H.; Aoki, H.; Okagawa, T.; Mimatsu, K. Effects of electric current on chondrogenesis in vitro. Clin. Orthop. Relat. Res. 1982, 163, 243-247. [CrossRef]

46. Chao, P.H.; Roy, R.; Mauck, R.L.; Liu, W.; Valhmu, W.B.; Hung, C.T. Chondrocyte translocation response to direct current electric fields. J. Biomech. Eng. 2000, 122, 261-267. [CrossRef] [PubMed]

47. Akanji, O.O.; Lee, D.A.; Bader, D.A. The effects of direct current stimulation on isolated chondrocytes seeded in 3D agarose constructs. Biorheology 2008, 45, 229-243. [CrossRef] [PubMed]

48. Kwon, H.J.; Lee, G.S.; Chun, H. Electrical stimulation drives chondrogenesis of mesenchymal stem cells in the absence of exogenous growth factors. Sci. Rep. 2016, 6, 39302. [CrossRef] [PubMed]

49. Hiemer, B.; Krogull, M.; Bender, T.; Ziebart, J.; Krueger, S.; Bader, R.; Jonitz-Heincke, A. Effect of electric stimulation on human chondrocytes and mesenchymal stem cells under normoxia and hypoxia. Mol. Med. Rep. 2018, 18, 2133-2141. [CrossRef] [PubMed]

50. Farr, J.; Mont, M.A.; Caldwell, J.R.; Garland, D.; Zizic, T.M. Pulsed electrical stimulation in patients with osteoarthritis of the knee: Follow up in 288 patients who had failed non-operative therapy. Surg. Technol. Int. 2006, 15, 227-233.

51. Garland, D.; Holt, P.A.; Harrington, J.T.; Caldwell, J.R.; Zizic, T.M.; Cholewczynski, J. A 3-month, randomized, double-blind, placebo-controlled study to evaluate the safety and efficacy of a highly optimized, capacitively coupled, pulsed electrical stimulator in patients with osteoarthritis of the knee. Osteoarthr. Cartil. 2007, 15, 630-637. [CrossRef] [PubMed]

52. Rodan, G.A.; Bourret, L.A.; Norton, L.A. DNA synthesis in cartilage cells is stimulated by oscillating electric fields. Science 1978, 199, 690-692. [CrossRef] [PubMed]

53. Fitzsimmons, R.J.; Gordon, S.L.; Kronberg, J.; Ganey, T.; Pilla, A.A. A pulsing electric field (PEF) increases human chondrocyte proliferation through a transduction pathway involving nitric oxide signaling. J. Orthop. Res. 2008, 26, 854-859. [CrossRef]

54. Esfandiari, E.; Roshankhah, S.; Mardani, M.; Hashemibeni, B.; Naghsh, E.; Kazemi, M.; Salahshoor, M. The effect of high frequency electric field on enhancement of chondrogenesis in human adipose-derived stem cells. Iran. J. Basic Med. Sci. 2014, 4, 571-576.

55. Mardani, M.; Roshankhah, S.; Hashemibeni, B.; Salahshoor, M.; Naghsh, E.; Esfandiari, E. Induction of chondrogenic differentiation of human adipose-derived stem cells by low frequency electric field. Adv. Biomed. Res. 2016, 5, 97. [CrossRef] [PubMed]

56. Brighton, C.T.; Unger, A.S.; Stambough, J.L. In Vitro Growth of Bovine Articular Cartilage Chondrocytes in Various Capacitively Coupled Electrical Fields. J. Orthop. Res. 1984, 2, 15-22. [CrossRef] [PubMed]

57. Wang, W.; Wang, Z.; Zhang, G.; Clark, C.C.; Brighton, C.T. Up-regulation of chondrocyte matrix genes and products by electric fields. Clin. Orthop. Relat. Res. 2004, 427, S163-S173. [CrossRef] [PubMed]

58. Brighton, C.T.; Wang, W.; Clark, C.C. Up-regulation of matrix in bovine articular cartilage explants by electric fields. Biochem. Biophys. Res. Commun. 2006, 342, 556-561. [CrossRef] [PubMed]

59. Brighton, C.T.; Wang, W.; Clark, C.C. The effect of electrical fields on gene and protein expression in human osteoarthritic cartilage explants. J. Bone Jt. Surg. 2008, 90, 833-848. [CrossRef] [PubMed]

60. Xu, J.; Wang, W.; Clark, C.C.; Brighton, C.T. Signal transduction in electrically stimulated articular chondrocytes involves translocation of extracellular calcium through voltage-gated channels. Osteoarthr. Cartil. 2009, 17, 397-405. [CrossRef] [PubMed]

61. Brighton, C.T.; Wang, W.; Clark, C.C.; Praestgaard, A. A Spectrophotometric Analysis of Human Osteoarthritic Cartilage Explants Subjected to Specific Capacitively Coupled Electric Fields. Open J. Biophys. 2013, 158-164. [CrossRef]

62. Hernández-Bule, M.L.; Paíno, C.L.; Trillo, M.Á.; Úbeda, A. Electric stimulation at 448 kHz promotes proliferation of human mesenchymal stem cells. Cell. Physiol. Biochem. 2014, 34, 1741-1755. [CrossRef] [PubMed] 
63. Vaca-González, J.J.; Guevara, J.M.; Vega, J.F.; Garzón-Alvarado, D.A. An In Vitro Chondrocyte Electrical Stimulation Framework: A Methodology to Calculate Electric Fields and Modulate Proliferation, Cell Death and Glycosaminoglycan Synthesis. Cell. Mol. Bioeng. 2016, 9, 116-126. [CrossRef]

64. Vaca-González, J.J.; Escobar, J.F.; Guevara, J.M.; Hata, Y.A.; Gallego Ferrer, G.; Garzón-Alvarado, D.A. Capacitively coupled electrical stimulation of rat chondroepiphysis explants: A histomorphometric analysis. Bioelectrochemistry 2019, 126, 1-11. [CrossRef] [PubMed]

65. Vaca-González, J.J. The Effect of Electric Fields on Hyaline Cartilage: An in vitro and in Silico Study. Ph.D. Thesis, Universidad Nacional de Colombia, Bogotá, Colombia, Universitat Politècnica de València, Valencia, Spain, 2019. [CrossRef]

66. Holmes, J.W. Model First and Ask Questions Later: Confessions of a Reformed Experimentalist. J. Biomech. Eng. 2019, 141, 074701. [CrossRef] [PubMed]

67. Doulabi, A.H.; Mequanint, K.; Mohammadi, H. Blends and nanocomposite biomaterials for articular cartilage tissue engineering. Materials (Basel) 2014, 7, 5327-5355. [CrossRef] [PubMed]

68. Ansari, M.; Eshghanmalek, M. Biomaterials for repair and regeneration of the cartilage tissue. Bio-Design Manuf. 2019, 2, 41-49. [CrossRef]

69. Madeira, C.; Santhagunam, A.; Salgueiro, J.B.; Cabral, J. Advanced cell therapies for articular cartilage regeneration. Trends Biotechnol. 2015, 33, 35-42. [CrossRef] [PubMed]

70. Jacob, J.; More, N.; Kalia, K.; Kapusetti, G. Piezoelectric smart biomaterials for bone and cartilage tissue engineering. Inflamm. Regen. 2018, 38, 2. [CrossRef] [PubMed]

71. Flory, P.J. Principles of Polymer Chemistry; Cornell University Press: Ithaca, NY, USA, 1953.

72. Donnan, F.G. The theory of membrane equilibria. Chem. Rev. 1924, 1, 73-90. [CrossRef]

73. Shiga, T.; Kurauchi, T. Deformation of polyelectrolyte gels under the influence of electric field. J. Appl. Polym. Sci. 1990, 39, 2305-2320. [CrossRef]

74. Doi, M.; Matsumoto, M.; Hirose, Y. Deformation of Ionic Polymer Gels by Electric Fields. Macromolecules 1992, 25, 5504-5511. [CrossRef]

75. Grimshaw, P.E.; Nussbaum, J.H.; Grodzinsky, A.J.; Yarmush, M.L. Kinetics of electrically and chemically induced swelling in polyelectrolyte gels. J. Chem. Phys. 1990, 93, 4462-4472. [CrossRef]

76. Lai, W.M.; Hou, J.S.; Mow, V.C. A triphasic theory for the swelling and deformation behaviors of articular cartilage. J. Biomech. Eng. 1991, 113, 245-258. [CrossRef]

77. Gu, W.Y.; Lai, W.M.; Mow, V.C. A Mixture Theory for Charged-Hydrated Soft Tissues Containing Multi-electrolytes: Passive Transport and Swelling Behaviors. J. Biomech. Eng. 1998, 120, 169-180. [CrossRef] [PubMed]

78. Mow, V.C.; Kuei, S.C.; Lai, W.M.; Armstrong, C.G. Biphasic creep and stress relaxation of articular cartilage in compression: Theory and experiments. J. Biomech. Eng. 1980, 102, 73-84. [CrossRef] [PubMed]

79. Zhou, X.; Hon, Y.C.; Sun, S.; Mak, A.F.T. Numerical simulation of the steady-state deformation of a smart hydrogel under an external electric field. Smart Mater. Struct. 2002, 11, 459-467. [CrossRef]

80. Li, H.; Yuan, Z.; Lam, K.Y.; Lee, H.P.; Chen, J.; Hanes, J.; Fu, J. Model development and numerical simulation of electric-stimulus-responsive hydrogels subject to an externally applied electric field. Biosens. Bioelectron. 2004, 19, 1097-1107. [CrossRef] [PubMed]

81. Wallmersperger, T.; Kröplin, B.; Holdenried, J.; Gülch, R.W. A Coupled multi-field-formulation for ionic polymer gels in electric fields. In Proceedings of the SPIE's 8th Annual International Symposium on Smart Structures and Materials, Beach, CA, USA, 3-8 March 2001; pp. 264-275. [CrossRef]

82. Wallmersperger, T.; Kröplin, B.; Gülch, R.W. Coupled chemo-electro-mechanical formulation for ionic polymer gels-Numerical and experimental investigations. Mech. Mater. 2004, 36, 411-420. [CrossRef]

83. Ghantasala, M.K.; Suthar, K.J.; Mancini, D.C. Steady-State Simulation of the Chemo-Electro-Mechanical Behaviour of Hydrogels. Int. J. Model. Simul. 2010, 30, 396-404. [CrossRef]

84. Logg, A.; Mardal, K.A.; Wells, G.N. (Eds.) Automated Solution of Differential Equations by the Finite Element Method_The FEniCS Book; Springer: Berlin/Heidelberg, Germany, 2012. [CrossRef]

85. Ayachit, U. The ParaView Guide: A Parallel Visualization Application; Kitware, Inc.: Clifton Park, NY, USA, 2015.

86. Geuzaine, C.; Remacle, J.F. Gmsh: A 3-D finite element mesh generator with built-in pre- and post-processing facilities. Int. J. Numer. Methods Eng. 2009, 79, 1309-1331. [CrossRef]

87. Van Rienen, U. Numerical Methods in Computational Electrodynamics_Linear Systems in Practical Applications, 1st ed.; Springer: Berlin/Heidelberg, Germany, 2001. [CrossRef] 
88. Langtangen, H.P.; Mardal, K.A. Introduction to Numerical Methods for Variational Problems, 1st ed.; Texts in Computational Science and Engineering; Springer International Publishing: Cham, Switzerland, 2019. [CrossRef]

89. Helfferich, F. Ion Exchange; McGraw-Hill Book Company, Inc.: New York, NY, USA, 1962.

90. Nernst, W. Zur Kinetik der in Lösung befindlichen Körper. Z. für Phys. Chem. 1888, 2U, 613-637. [CrossRef]

91. Nernst, W. Die elektromotorische Wirksamkeit der Jonen. Z. für Phys. Chem. 1889, 4U, 129-181. [CrossRef]

92. Planck, M. Ueber die Erregung von Electricität und Wärme in Electrolyten. Ann. Phys. 1890, 275, 161-186. [CrossRef]

93. Bruce, P.G. (Ed.) Solid State Electrochemistry; Cambridge University Press: Cambridge, UK, 1995. [CrossRef]

94. Abali, B.E. Computational Reality_Solving Nonlinear and Coupled Problems in Continuum Mechanics; Springer: Singapore, 2017. [CrossRef]

95. Brezzi, F.; Fortin, M. (Eds.) Mixed and Hybrid Finite Element Methods; Springer Series in Computational Mathematics; Springer: New York, NY, USA, 1991; Volume 15. [CrossRef]

96. Larson, M.G.; Bengzon, F. The Finite Element Method: Theory, Implementation, and Applications; Springer: Berlin/Heidelberg, Germany, 2013. [CrossRef]

97. Gockenbach, M.S. Understanding and Implementing the Finite Element Method; Society for Industrial and Applied Mathematics: Philadelphia, PA, USA, 2006. [CrossRef]

98. Huyghe, J.M.; Janssen, J.D. Quadriphasic Mechanics of Swelling Incompressible Porous Media. Int. J. Eng. Sci. 1997, 35, 793-802. [CrossRef]

99. Yu, C.; Malakpoor, K.; Huyghe, J.M. A three-dimensional transient mixed hybrid finite element model for superabsorbent polymers with strain-dependent permeability. Soft Matter 2018, 14, 3834-3848. [CrossRef] [PubMed]

100. Basser, P.J.; Grodzinsky, A.J. The Donnan model derived from microstructure. Biophys. Chem. 1993, 46, 57-68. [CrossRef]

101. Buschmann, M.D.; Grodzinsky, A.J. A molecular model of proteoglycan-associated electrostatic forces in cartilage mechanics. J. Biomech. Eng. 1995, 117, 179-192. [CrossRef] [PubMed]

102. Overbeek, J. The Donnan Equilibrium. Prog. Biophys. Biophys. Chem. 1956, 6, 57-84. [CrossRef]

103. Gülch, R.W.; Holdenried, J.; Weible, A.; Wallmersperger, T.; Kröplin, B. Polyelectrolyte gels in electric fields: A theoretical and experimental approach. In Proceedings of the SPIE's 7th Annual International Symposium on Smart Structures and Materials, Beach, CA, USA, 6-8 March 2000; Volume 3987, pp. 193-202. [CrossRef]

104. Patel, J.M.; Saleh, K.S.; Burdick, J.A.; Mauck, R.L. Bioactive factors for cartilage repair and regeneration: Improving delivery, retention, and activity. Acta Biomater. 2019, 93, 222-238. [CrossRef] [PubMed] 